e-ISSN: 1984-4255 ARGUMENTOS

D0l: https://doi.org/10.36517/Argumentos.24.10

\title{
Metafísica da informação em um quadro referencial tridimensional
}

\author{
Metaphysics of information in a \\ tridimensional conceptual framework
}

Ralph Leal Heck

Orcid: http://orcid.org/0000-0002-9827-1743 - E-mail imagomundi@hotmail.com

\begin{abstract}
RESUMO
O objetivo deste estudo é expandir um dos assuntos que desenvolvi em minha pesquisa doutoral e apontar desenvolvimentos que ampliem o valor filosófico do tópico. A tarefa consiste em pavimentar o terreno para a construção de uma teoria metafísica tridimensional, centrada no conceito de informação. A primeira dimensão desta teoria é uma epistemologia informacional baseada nos levels of abstraction de Floridi. A segunda dimensão (semântico-pragmática) é baseada na filosofia da linguagem de Brandom e a terceira dimensão é baseada na ontologia de processo de Seibt. O resultado é um quadro referencial teórico metafísico versátil e dinâmico, que procura manter a eficiência do modelo metafísico clássico de propriedade-ente-substância, dotado de um núcleo metafísico da ontologia de processo. A tarefa de exposição desta teoria Floridi-Brandom-Seibt se divide em quatro etapas. Na primeira, darei uma definição geral de informação. Na segunda, definirei informação pragmática a partir do arcabouço conceitual elaborado por Robert Brandom. Estas duas etapas resultam de uma pesquisa parcialmente elaborada em minha tese. As duas etapas seguintes são um conjunto de reflexões que, até o momento, considero relevantes e profícuas possibilidades de desenvolvimento. $\mathrm{A}$ terceira etapa da exposição segue Luciano Floridi e propõe o deslocamento do conceito de informação como um produto de ações, desenvolvido na etapa anterior, para o papel de categoria central que constituirá a composição e compreensão do próprio mundo povoado por ações, entidades, eventos e processos. A quarta e última etapa desta reflexão procura vislumbrar o deus ex maquina da visão informacional de Floridi, revelando uma ontologia de processos como substrato último, de onde deve emergir o conceito de informação como tentativa de discretizar o continuum dos processos que perfaz a realidade.
\end{abstract}

Palavras-chave: Informação. Epistemologia. Brandom. Ontologia de processo. Metafísica. 


\section{ABSTRACT}

The purpose of this study is to expand one of the subjects that I aimed in my doctoral research and to point out developments in order to expand the philosophical value of the topic. The task consists of paving the ground for the construction of a three-dimensional metaphysical theory centered on the concept of information. The first dimension of this theory is an informational epistemology based on Floridi's levels of abstraction. The second dimension (semantic-pragmatic) is based on Brandom's philosophy of language and the third dimension is based on Seibt's process ontology. The result is a versatile and dynamic theoretical metaphysical framework, which seeks to maintain a classic metaphysical model of property-entity-substance with a metaphysical core of process ontology. The task of exposing this Floridi-Brandom-Seibt theory is divided into four stages. In the first, I will give a general definition of information. In the second, I will define pragmatic information from the conceptual framework developed by Robert Brandom. These two steps results from a research partially developed in my thesis. The next two stages constitute a set of reflections that, so far, I consider relevant and possible further development. The third stage of the exhibition follows Luciano Floridi proposing the displacement of the concept of information as a product of actions developed in the previous stage, towards the central category role that constitutes the composition and understanding of the world itself shared by actions, entities, events and processes. A fourth and final stage of this reflection seeks to glimpse the deus ex maquina in Floridi's informational vision, revealing a process ontology as the ultimate substrate, where the concept of information must emerge as an attempt to differentiate or continue the processes that make up reality.

Keywords: Information. Epistemology. Brandom. Process Ontology. Metaphysics.

\section{O que é informação?}

Há muitas definições de informação. Usualmente elas são cunhadas para satisfazer as demandas de uma área específica, para solucionar problemas particulares. Fala-se de informação como significado, como representação auferida de uma mensagem. Informação como controle de probabilidade, redução de incertezas, redução da aleatoriedade. Informação como estratégias de computação, como algoritmos, etc.

Losee, entretanto, apresenta uma definição mais geral de informação que tomarei como ponto de partida: Informações são produzidas por quaisquer processos e refletem as mudanças das características destes processos, auferido na saída de etapas ou do processo como um todo (1997. p.256). Esta definição geral procura organizar em uma única classe a maioria dos conceitos de informação em disciplinas individuais. Onde a quantificação de valores possíveis na saída e suas frequências relativas de ocorrência podem ser usadas na medição da quantidade de informação ${ }^{1}$. Esta definição busca vincular o que ocorre e o que existe ao como algo ocorre e como existe. Aqui, o conceito de informação está fundamentalmente vinculado ao de processo. Examinar um determinado estado de coisas, objeto ou situação, nos fornece informação sobre seus constituintes e sobre o processo de composição deles; explica-nos como as partes de $x$ estão em determinado processo tal que formem $x$. Tomemos um pão como exemplo. Examinar um pão é obter informações sobre seus ingredientes (se são ou não de qualidade) e sobre como estes ingredientes são manipulados para formá-lo. E também é saber quais são as

\footnotetext{
1 Valores que podem ser qualificados fisicamente, probabilisticamente, algoritmicamente, semanticamente.
} 
consequências, possibilidades e impossibilidades que se abrem de agora para frente, depois de termos constatado que aquilo era um pão. O que me leva a crer, ao contrário do que defende Losee, que a informação tem um valor intrínseco de ação. Ela expressa a mudança passada, possivelmente futura e a estrutura, entendida como as relações internas (formais ou materiais), dos sistemas no qual estas mudanças ocorrem.

Suponhamos que deseje fazer um pudim de pão. As informações que obtive na análise do pão servirão para construir as informações sobre o pudim de pão. A partir do acoplamento dos sistemas pão-pudim de pão, obtenho informações dos ingredientes e dos processos inerentes aos sistemas em um crescente interconectado informativo. Tais sistemas não necessitam partilhar todos os componentes elementares. Eu poderia obter informação de uma situação como a boa ou má recepção ao servir pudim de pão em uma festa junina. Saber como e do que um pão é feito, como e do que um pudim de pão é feito, como e do que é feita uma festa junina e como e do que são satisfeitas as expectativas dos convidados, nos garante informações sobre todos estes processos acoplados em um continuum.

O que temos aqui, é que os processos envolvidos em cada etapa partilham alguns elementos, mas são observados a partir de ângulos diversos, participando de situações de análise diversas, interagindo com outros processos em planos de análise diferentes, podendo ocorrer logicamente antes, depois ou simultaneamente. Neste sentido, vale recordar do texto de Heráclito sobre a água salgada: uma mesma porção de água salgada pode ser deletéria para o humano, mas benéfica para o peixe. No processo o qual o homem participa a água salgada tem um efeito oposto ao efeito no qual o peixe do mar participa. Claro que estamos descrevendo processos que ocorrem em um plano aproximado. Nos referimos a efeitos em entidades biológicas e classificamos os efeitos como benéficos, ou maléficos. Mas poderíamos dizer que se quiséssemos comer o peixe marinho, soltá-lo na água salgada seria maléfico para nosso intento. Claro que esperássemos esgotar todas as diferentes situações e possibilidades de recorte nunca terminaríamos. Pois, a resposta para a pergunta "quais recortes teóricos podemos escolher?" na passagem do senso comum à filosofia é demasiadamente grande. Ela nos remontaria à toda a filosofia.

Para evitar este longo percurso, escolhi uma abordagem que está vinculada a concepção clássica de ontologia da substância. Seguirei Floridi, afirmando que o modo mais eficiente e pedagógico de capturar esta interconexão é através de uma linguagem lógica funcional e uma teoria dos tipos. Com esta análise, podemos descrever as interações entre elementos de um mesmo sistema, interações de elementos entre sistemas de mesmo nível ou de níveis distintos, etapa a etapa, isto é, como se fosse um sistema discreto, além de sermos capazes de descrever a interação entre sistemas tomados como elementos de sistemas mais amplos.

Onde neste esquema de interações, retorno à Losse que chama a atenção para duas possibilidades fundamentais de conceber o comportamento da informação. Se determinado movimento do sistema admite ser totalmente reversível, dizemos que não há perda de informação. Mas, se o sistema admite apenas parcialmente ou não admite a reversibilidade, dizemos que há perda de informação, há informações irrecuperáveis. A tese central de Losse é que todo processo produz informação (p. 258) e a informação nos comunica qual foi o input do sistema e qual o processo que levou tal input ao output atual.

\section{O que é Informação pragmática?}

Apresentei a definição de informação que tenho em mente e um método elementar de auferi-la. Agora, devo esclarecer a base de onde erijo o conceito "pragmática" para compor a 
expressão "informação pragmática". Tomo como ponto de partida o pensamento de Robert Brandom. De fato, tomo para mim as três características fundamentais de sua filosofia da linguagem: a análise pragmática, a semântica inferencialista e a lógica expressivista. A análise pragmática de Brandom procura sintetizar as duas vertentes da filosofia analítica da linguagem: a filosofia da linguagem formal e a filosofia da linguagem ordinária. A primeira é marcada por investigar o caráter designativo-representacional da linguagem por meio de um aparato formal e a segunda investigar a linguagem enquanto uma dimensão histórico-natural das práticas sociais. A primeira dá ênfase à semântica e a segunda dá ênfase à pragmática da linguagem. A síntese de Brandom entende as práticas linguísticas naturais como uma elaboração sistemática, logicamente exprimível, do "jogo de dar e pedir razões" de onde se manifesta a própria racionalidade humana (OLIVEIRA, 2019, pp. 85-87). Este jogo ou, de modo mais local, os diversos jogos que compõem nossas práticas linguísticas são analisados a partir de quatro componentes, dois semântico-pragmáticos: a asserção e a inferência e dois componentes deônticos: autorizações e compromissos. Nestes termos, a pragmática fornece condições para a semântica. Mas, não uma semântica fundada na representação (nas imagens mentais, na figuração), mas uma semântica desenhada a partir de nossa capacidade de percorrer fluxos inferenciais. Estes fluxos são as razões do nosso jogo.

Nosso jogar do "jogo de dar e pedir razões" é formado por asserções (ações de asserir - compromissos doxásticos) que nos comprometem e autorizam a novas asserções. As normas que me habilitam a ir de uma asserção a outra são as inferências (formais e materiais). A cada lance no jogo, ou seja, a cada asserção, um conjunto de inferências pode ser feita revelando os próximos passos que se pode e os que se deve dar e quais deles não estão mais disponíveis.

Nestes termos, a semântica se consolida na pragmática, pois, assim compreendemos os conteúdos conceituais como razões de nossas atitudes e nossos atos ocorrentes em nossas inferências. Nós definimos os conceitos e relações por meio das inferências que estamos habilitados e impedidos de fazer a partir do momento que asserimos tais conceitos nas inferências. Assim, cada conceito desempenha um papel na cadeia de inferências, cada asserção expressa um elo na cadeia, e a inferência expressa um movimento de um elo à outro(s) nas cadeias de asserções. Portanto, a inferência é definida como a capacidade racional de operar asserções em que a asserção é a ação de expressar uma sentença em uma linguagem, tal que, os sons que emito na expressão desempenhem o papel funcional (functional role) de premissa ou conclusão de certa sequência.

Como essa cadeia de asserções é mediada por autorizações e compromissos, e que tais cadeias podem ser passadas a diante, herdadas e compartilhadas entre os falantes, podemos dizer que as regras que orientam nossas práticas linguísticas são histórico-socialmente gestadas. Portanto, o método da análise pragmático-inferencial de Brandom parte da elucidação das práticas sociais qualificadas como práticas linguísticas, organizadas por asserções e cadeias de inferências de modo a constituir os significados em nossa linguagem, já que eles se dão nas práticas locais de produzir e consumir atos de linguagem. A análise neste contexto é a explicitação das regras locais e de seu sistema subjacente que conferem significado às expressões que empregamos. Sobre o método de análise de Brandom, cito:

A estratégia explanatória perseguida aqui é começar com uma consideração sobre práticas sociais, identificar a estrutura particular que elas devem exibir para qualificálas especificamente como práticas linguísticas, e então considerar que diferentes tipos de conteúdos semânticos essas práticas podem conferir aos estados, performances e expressões apanhados neles de maneiras adequadas. (BRANDOM, 1994, p. xii). 
Deste modo, as inferências operam como movimentos na linguagem. E elas podem ser entendidas como formais ou materiais. As inferências materiais são o ponto de partida da semântica de Brandom, elas descrevem o relacionamento substitucional ou hierárquico não-lógico entre conceitos, de tal forma que a passagem da conclusão a partir das premissas depende exclusivamente do conteúdo das expressões e não de sua forma lógica, ou seja, das inferências que podemos fazer a partir deles e não da sua sintaxe. Já as inferências formais, são entendidas como aquelas que preservam a forma lógica do vocabulário, indiferente à substituição de vocábulos não-lógicos.

A lógica entra como ferramenta de explicitação destas relações conceituais materiais, daí seu expressivismo lógico. O vocabulário lógico é tomado como o tipo de vocabulário meIhor desenvolvido para explicitar as relações entre asserções e inferências. Este vocabulário passa a ser privilegiado por razões práticas, é o vocabulário melhor desenvolvido para fins de explicitar as regras no "jogo de dar e pedir razões". É claro que esta explicitação não ocorre de maneira imediata, nem autônoma. É a comunidade falante e os participantes do jogo quem determinarão o sucesso uns dos outros no andamento do jogo. Isto é nomeado por Brandom como a prática de contar escores. Cada um de nós acompanha a argumentação uns dos outros a fim de acompanhar e validar nossas asserções e as inferências que realizamos com elas. Dúvidas e erros demandam de nós correções, retratações ou, mais importante, a explicitação das regras que nos levaram a uma asserção ou inferência tida como problemática. A ação de explicitar uma regra é parte fundamental desta noção da racionalidade defendida por Brandom. Podemos indicar as regras, as regras das regras e assim recursivamente até o limite da exemplificação por uma ação como última instância de explicitação das regras. O interessante deste percurso, entretanto, é que até o movimento da ação final, a lógica é a melhor ferramenta disponível para a explicitação das regras.

Seguindo, portanto, a orientação desta filosofia, formalizei em minha tese um sistema que parametriza situações de diálogo, isto é, jogos locais. No interior deste sistema, formalizei os agentes que jogam o jogo. O sistema de diálogo é construído com foco nas regras de inferência de autorização, compromisso e incompatibilidades de que disporão os agentes no decurso do diálogo ${ }^{2}$, este sistema conta com regras formais que autorizam a modificação das próprias regras durante o jogo. Já os agente são definidos de modo mais estático, operando com registros de asserções, regras de inferência formal e material e uma listagem de componentes subsentenciais que podem ser eliminados, adicionados ou combinados a qualquer momento via certas regras estruturais epistêmicas.

Diante deste cenário, podemos agora nos perguntar: onde está a informação pragmática? A primeira tentação seria entender a informação como a representação que resulta das asserções. Mas, isto conflita com o quadro referencial teórico que escolhi. A representação resulta das inferências que nos levam a determinada asserção somada às inferências que podemos fazer a partir desta asserção. A própria ideia de representação é um recorte no fluxo de inferências que tem em sua intercessão determinados componentes subsentenciais, mas que não captura a essência da linguagem, não captura a linguagem em seu movimento constitutivo. Portanto, falar de informação vinculada à semântica representacionalista seria apenas arranhar a superfície do significado de informação que procuro dar.

Diante disto, elegerei uma instância mais profunda de onde poderia emergir um conceito de informação. Uma que pudesse levar a diante a máxima "a informação é o que a in-

\footnotetext{
2 No caso limite desta interação, um dos interlocutores do diálogo por der a própria natureza. Isto ocorre em situações de investigação empírica.
} 
formação faz" ${ }^{3}$. Segundo nossa definição inicial, a informação está relacionada com o output e o processo de um dado input. Ora, note que no contexto de Brandom, a informatividade seria a identificação dos compromissos e autorizações que se seguem de determinada asserção e quais as regras que constituem as inferências que me levam a tais compromissos e autorizações ${ }^{4}$. Onde a reversibilidade e a irreversibilidade da informação, neste caso, são dadas pela recuperação ou perda de compromissos e autorizações no decurso de nossas práticas linguísticas 5 .

Buscando um modo de identificar e quantificar objetivamente esta informação pragmática reconheci dois níveis informacionais. O primeiro diz respeito ao sujeito. Uma determinada asserção é informativa se ela é minimamente incoerente e maximamente relevante ${ }^{6}$ para o sujeito. Isto é, a partir de determinada asserção, fazemos o mínimo possível de ajustes em nossas crenças e esta asserção aumenta o conjunto de asserções que podemos fazer. Este seria um equacionamento ideal das asserções, portanto um cenário de informatividade máxima. É possível avaliar casos menos amigáveis, como uma informação que demanda muitas modificações em minhas crenças anteriores e que tenham poucas consequências não-triviais.

Já o segundo nível de informatividade pertence à classe das regras que medeiam o jogo de linguagem entre os sujeitos. Este nível de avaliação informativa entra em atividade quando somos interpelados para explicitarmos as regras que orientam nossas inferências. Aqui, a informatividade é medida pela capacidade que determinada asserção, expressando uma regra, tem de ampliar a classe de inferências que medeiam o jogo. Neste sentido, podemos aplicar a informatividade recursivamente para classes de regras cada vez mais abstratas, arrisco dizer, embora não tenha provado, que podemos ampliar aos níveis filosófico e meta-filosófico de abrangência de regras. Onde a reversibilidade e a irreversibilidade da informação, neste caso, são definidas pela recuperação ou perda das regras no decurso de nossas práticas linguísticas.

\section{Filosofando sobre a informação pragmática: uma virada informacional}

Este ponto indica até onde cheguei na investigação deste assunto em minha tese (HECK, 2018). O que vem a seguir resulta de um conjunto de reflexões e hipóteses elaboradas sobre como expandir metafisicamente o conceito de informação pragmática. Se da perspectiva epistemológica avancei com a proposta de avaliação da informação e nossas práticas linguísticas (portanto, de forte natureza epistêmica), é necessário avançar para o outro lado da moeda metafísica. Para fazer isto, a teoria da informação pragmática deve tematizar alguma ontologia e a julgar pelos trabalhos de Brandom e antes dele Wittgenstein, esta tarefa não pode ser concluída com um recurso direto da pragmática à metafísica. Mas, antes, por uma série de passagens que visem deixar para trás gradualmente a ontologia da tradição e aproximar-se de uma ontologia que incorpore o movimento que também é fundamento da pragmática.

A primeira passagem da dimensão epistêmica para a dimensão ontológica será feita utilizando o argumento de Luciano Floridi sobre o papel da informação na nossa atual compreensão de mundo. $O$ mundo em que vivemos é atravessado por elementos, propriedades e en-

\footnotetext{
${ }^{3}$ Em um sentido linguístico pragmático "a linguagem é o que a linguagem faz" - o significado é o uso em um dado contexto prático.

${ }^{4}$ E em um nível linguístico mais fundamental, a determinibilidade do próprio sentido da linguagem. O fazer tornado expresso pelo fazer da linguagem e as expressões da linguagem significadas pelo que podemos fazer com elas.

${ }^{5}$ Apresentando um comportamento formal semelhante relações inferenciais simétricas e assimétricas de Brandom (1994).

${ }^{6}$ Minimamente incoerente quer dizer: demanda do indivíduo o menor número possível de revisões sobre suas crenças. E maximamente relevante quer dizer: se ao incorporar aquela informação, o sujeito aumenta a quantidade de inferências não triviais que é capaz de fazer.
} 
tidades que foram vislumbradas desde a ontologia tradicional e hoje encontrando formulações cada vez mais elaboradas (Cf. OLIVEIRA, 2014).

Neste cenário, o universo virtual passou a integrar um importante domínio com seu substrato, entidades, propriedades e relações que nos afetam, orientando as sociedades e nosso modo de interagir com a própria realidade, nos impelindo a considerar a dimensão das relações informacionais como extremamente relevante para a compreensão da realidade no sentido metafísico mais próprio. Nossa astronomia capta informações das estrelas e buracos negros por meio de equipamentos que não mais dependem dos nossos sentidos para ser bem sucedidos, a mecânica quântica possui conceitos de transferência de informação que desafiam a estrutura do espaço-tempo, portanto, da nossa cognição. Nossas batalhas eleitorais são orientadas pelas informações coletadas em comunidades virtuais, e pela desinformação difundida nelas, realizando um verdadeiro movimento de condicionamento coletivo inescapável. Nosso sistema econômico especulativo é orientado por Inteligências artificiais especializadas em investimento que tem papel na determinação do futuro de nações inteiras. Esta relação entre nós, a natureza e a informação tem se tornado tão estreita que alguns filósofos tem se aventurado na elaboração de ontologias informacionais. Ontologias que têm na informação sua categoria fundamente.

Mas, serei comedido neste quesito. Minha proposta é apenas uma mudança heurística de olhar sobre a realidade, deslocando a informação para uma dimensão ontológica. Se esta proposta for coerente, então valerá a pena nos perguntarmos que tipo de ontologia poderíamos ter para dar suporte a este olhar informacional.

Floridi propõe o seguinte: se o universo informacional, nomeado de infoesfera, está cada vez mais robusto, produzindo mais resultados. Então, deveríamos ver todos os entes a partir de um prisma informacional. Isto quer dizer, tudo é informação. Tudo pode ser pensado em processos que envolvem a mudança de estados e interações entre processos que procuram resistir à entropia. Sejam os organismos vivos em seu acoplamento com o ambiente, sejam objetos inanimados que inexoravelmente se transformam ou erodem, sejam psiques, pensamentos, ficções, conceitos, culturas, hábitos. Tudo pode ser encarado como produtos informacionais. Deste modo, obtemos um nivelamento mínimo para o estatuto dos entes: o que tratar da informação tratará do que é comum a todos os entes. Neste plano de análise, o conceito de informação é considerado a categoria ontológica básica.

A informação pragmática, nestes termos metafísicos, poderia ser entendida como o conhecimento do devir das coisas em função da interação de seus estados atuais. Trazendo esta afirmação para o pragmatismo inferencialista, nos deparamos com uma concepção antropomorfizadora dos fenômenos naturais (autorizações e compromissos de animais, objetos e processos). Esta perspectiva é já antevista por Brandom na obra Making It Explicit, entendendo nossa compreensão do não-humano como uma extensão de nossa leitura das autorizações, compromissos e relações de incompatibilidade que constroem nossas práticas linguísticas. Esta concepção nos permitirá afirmar o caráter intrínseco de utilidade da informação.

Projetamos e atribuímos às coisas nossos próprios mecanismos de ação e significação ${ }^{7}$. Uma árvore, um gato, um fóton ou o Papai Noel se tornam cognoscíveis e passíveis de parti-

\footnotetext{
${ }^{7}$ Esta tese, no fundo, é uma variante da filosofia transcendental. Uma exigência oculta da primazia da dimensão pragmática que pode ser conferida na seguinte passagem do Making it Explicit: "The conception of concepts as inferentially articulated permits a picture of thought and of the world that thought is about as equally, and in the favored cases identically, conceptually articulated. Facts are just true claims. Facts, like other claims, are conceptually articulated by their inferential and incompatibility relations to other claims. It is a feature of the conceptual articulation of claims, and hence of facts, that they are about particular objects. (Indeed, the fact that we are accustomed to saying that facts, like claims, are about objects, rather than that they somehow consist of objects, is evidence for the correctness of identifying facts with true claims.) It is these facts and the propertied and related
} 
cipação em nossa linguagem na medida em que os entendemos por meio de fluxos inferenciais e como agentes atribuíveis de autorizações e compromissos, característicos de suas ações e vicissitudes.

Assim, a informação pragmática não se restringirá ao que se pode inferir a partir de determinada asserção ou regra acerca de agentes racionais, mas o que se pode inferir a partir de determinada modificação de estado ou regra acerca de qualquer tipo de entidade informacional e este é seu caráter de utilidade intrínseca. Já que, de acordo com Floridi, as entidades informacionais são coextensivas com a realidade, a informação pragmática nos permite identificar o abrir e fechar das possibilidades e impossibilidades de curso a partir de cada ranger das catracas de variados tamanhos e velocidades que compõem a multiplicidade de processos da realidade.

Mas, como tornar discreto este fluxo de informações que atravessam simultaneamente as coisas em diferentes níveis de interação? Como identificar quais processos devem ser exaltados e quais devem ser relevados?

Uma possibilidade é seguir Floridi e adotar o conceito de níveis de abstração (Levels of Abstraction - LoAs) como heurística para a seleção destes processos. Mas, o que são os LoAs? LoAs são modelagens discretas sobre processos contínuos. Que entendem a participação de entidade informacionais em diferentes sistemas simultaneamente.

Tomemos um exemplo: Carla, Maria e João estão conversando acerca de um celular em uma loja. Carla é uma influenciadora digital, Maria é engenheira e João, economista. Cada um deles realizará inferências a partir de seus próprios interesses e conhecimentos. Maria observará o status do aparelho, seu design, sua boa capacidade de tirar fotos, editá-las e a duração da bateria. Maria observará quem é a montadora, a qualidade dos componentes do aparelho (duração da bateria incluso), se ele é compatível com outras tecnologias. João observará a variação de preço do produto, o custo de manutenção e as formas de pagamento. Cada um destes modos se constitui um nível de abstração. Que podem ser analisados paralelamente ou interconectados e interdependentes. Fornecendo diferentes modelos. Mas, note que aqui que, diferente de Floridi, a modelagem deve ser construída inferencialmente. Com conjuntos de asserções, inferências e regras relevantes para a situação. Estes níveis de abstração podem ser inclusive conflitantes levando a um tratamento em níveis mais abstratos ou menos abstratos de certas incompatibilidades. É neste contexto que surge a informatividade pragmática. Um lance, uma asserção, é uma ação simultaneamente em diversos planos e níveis de abstração. A informatividade seria a avaliação de determinada asserção ou mudança de estado em vista da mudança de classe de consequências e regras em dado nível de abstração.

Assim, o mesmo “jogo de dar e pedir razões" levantado por Brandom além de poder ser reproduzido pelos Níveis de abstração, ele pode vir a ser refinado. Cada LoA de Carla, Maria e Jogão corresponderia a um jogo com asserções e regras distintas, ocorrendo simultaneamente em uma mesma situação de fala. Uma mesma asserção teria valores e pesos distintos em cada subsistema que compõe o sistema total da situação provisoriamente demarcada em questão.

Assim, se cada coisa é informação e elas se entrelaçam em um contínuo de processos, que demarcamos discretamente para fins práticos, a informação pragmática seria a expressão das vicissitudes internas aos sistemas demarcados. Tais vicissitudes seriam expressas em termos

objects they involve that are cited as stimuli by interpreters who are specifying the reliable differential responsive dispositions in which the contents of empirical contents originate. These noninferential dispositions (the locus of our empirical receptivity) accordingly do not constitute the interface between what is conceptually articulated and what is not, but merely one of the necessary conditions for a conceptually articulated grasp of a conceptually articulated world-the world consisting of everything that is the case, all the facts, and the objects they are about" (BRANDOM, 1998. p. 622). 
de asserções e inferências orientadas por relações de compromisso, autorização e incompatibilidade e a ontologia da informação pragmática passaria a ser a outra face da moeda do "jogo de dar e pedir razões".

Se por um lado - o epistêmico, estas relações definem o significado e a relevância dos lances, é na compreensão ontológica ${ }_{L}$ com uma semântica própria associada, que estas relações só podem ser definidas a partir de um cenário de processos, onde a sistematização deste cenário constitui a dimensão descritiva e normativa dos limites das relações. Mas, que semântica está em jogo para que sejamos capazes de capturar linguística e epistemicamente estes processos? Seguirei aqui Mourelatos (1978. p.424ss) que distingue tipos de ocorrências linguísticas a diferenciar e se referir à processos: os processos como classes de ocorrências e de expressões que manifestam inferências analógicas entre processos de um lado, eventos e coisas do outro $^{8}$. Na medida em que, sem esta demarcação, não reconheceríamos a entrada e a saída entre os jogos. Isto é, de uma perspectiva epistemológica, temos os jogos de dar e pedir razões, de uma perspectiva ontológica, temos os processos informacionais e as coisas como objetos informacionais heuristicamente definidas como temporariamente estáticas. Assim, nos resta esclarecer o que são processos e os pressupostos de uma tal ontologia.

\section{Em direção a uma ontologia de processos}

É claro que se poderia objetar que a definição destes processos é também um jogo de dar e pedir razões. $O$ que nos colocaria em um círculo vicioso. A resposta é sim. Mas, esta postura não é circular. Ela é espiralar, na medida em que a descrição dos processos enquanto estruturais do jogo de dar e pedir razões nos leva a um nível conceitual cada vez mais amplo, mais fundamental em relação àquele que estamos a descrever e, assim por diante, até que toquemos o leito rochoso dos processos puros, i.e. sem referência aos habitantes da ontologia da substância. Desta ótica, podemos vislumbrar camadas acima de qualquer natureza (física, biológica, comportamental, cultural, etc.). Este limite conceitual é o ponto em que vislumbro chegar no horizonte de investigação da filosofia da informação pragmática. Neste nível, não há agentes ou entidades estáticas, apenas processos, que servirão de substrato mais fundamental que a informação entendida como a entidade básica e, portanto, pressuposto a toda discussão sobre informação pragmática.

Esta escolha se justifica pelo caráter heraclitiano que atravessa todas as instâncias do discurso sobre informação. Essa dimensão ontológica puramente processual pertence à filosofia de processo. Uma disciplina que encontra eco ao longo da história da filosofia e ganha contornos mais nítidos com os trabalhos de Whitehead e Resher. Johanna Seibt (2007, p. 296), representante desta metafísica, chama a atenção para os cuidados que devemos ao implementar uma ontologia desta natureza. O primeiro é livrar-se do "mito do dado" enunciado por Sellars, algo que a filosofia de Brandom, de onde construí o meu pensamento, já faz. O Segundo seria livrar-se do mito da substância (ibidem), para isto é necessário sobrepujar a resistência que a ontologia da substância oferece, dado seu valor histórico, colocando o conceito de dinamismo como predicado teórico analítico (2007. p.299), isto é: uma dada ontologia de processos deve conter dois traços: (i) a maioria das entidades básicas devem ser caracterizadas como dinâmicas. E (ii) o pre-

\footnotetext{
${ }^{8}$ Esta é uma reflexão inicial. Uma avaliação crítica e uma leitura formal desta semântica é o que considero como próxima etapa de investigação semântica, já que ela é baseada em linguagem natural. Uma leitura que me permita alternar entre ontologia de processos e a ontologia clássica da substância e que seja vinculável à semântica inferencial pragmática de Brandom, o que seria uma segunda etapa.
} 
dicado dinâmico não é redutível em tipos de entidades na teoria ontológica. Este dinamismo se apresenta de três modos: Como diferença dinâmica; produção; ou atividade.

Segundo Seibt, a diferença dinâmica é o encapsulamento recursivo de transições de estados em que a transição encapsulada é também parte da composição da transição encapsuladora. O dinamismo produtivo é um tornar-se em continuidade em uma onda de eventos. Já o processo como atividade, abdica da ideia de particularidade e determinação das entidades e as entidades passam a ser processos gerais concretos, dinâmicos, não-particulares e não-determinados (2007, p. 311).

\section{Conclusão}

Segundo o que vimos me parece razoável conceber que em termos ontológicos a informação serve, a partir de uma visão menos radical (OLIVEIRA, 2014. p.173), como heurística para uma ontologia de processos, além de nos habilitar ao longo de suas características epistemológicas a conceber esta ontologia como a outra face da moeda epistemológica da filosofia da informação, uma evidência nesta direção é o emprego do termo informação por Seibt (2007. p.305). Isto poderia levar, suponho, a entender que a ontologia da informação proposta por Floridi poderia ser uma camada mais abstrata, mais aproximada de uma epistemologia da informação, e ontologicamente decomponível em uma ontologia de processo.

Em uma opção mais radical, da perspectiva da ontologia de processo, a filosofia da informação que delineamos ao longo dos tópicos anteriores seria uma propedêutica que prepara o metafísico para uma visão dinâmica e sistemática de toda metafísica, que satisfaria uma grande quantidade de intuições científicas e filosóficas atuais.

Vale dizer que, nem mesmo o caráter pragmático da informação se perde neste processo de mudança da face metafísica. Seibt confirma um caráter praxiológico inerente à ontologia de processo que está em consonância com a pragmática da linguagem que defendi, uma vez que sugere que vivamos em

Um mundo de entidades em evolução e interação - entidades que são de modo intrínseco, relacionadas, mas cujo relacionamento não determina inteiramente o que somos. (...) de modo que quem nós somos será sempre uma matéria que nós mesmos moldamos para que nós sejamos. (SEIBT, 2007. p. 312).

O conceito pragmático que reaparece na filosofia da informação apresentada salienta exatamente este caráter. Um caráter que pode servir justamente de ponte para executarmos a passagem teórica da epistemologia para a ontologia (de processo) e vice-versa ao retornarmos às nossas práticas, um retorno que só é possível se estabelecermos uma compreensão ontológica processual de nosso jogo de dar e pedir razões ${ }^{9}$. Deste modo, construindo um esboço de uma teoria filosófica (eventualmente, um novo quadro teórico) tridimensional: uma metafísica da informação Floridi-Brandom-Seibt. Tal que, a informação seja a categoria

\footnotetext{
${ }^{9}$ No artigo Hegel e Filosofia Analítica, Brandom (2011, p. 85) explica sua passagem "da ordem semântica e da explicação ontológica, (...) para abarcar a metaconcepção, que requer inferência, a razão, enquanto primordial". O que pode a primeira vista significar um veto a possibilidade de uma ontologia. Em primeiro lugar, em seu discurso não há o abandono da concepção de fato ou juízo (vide toda a discussão e uso recorrente destas categorias em Making it Explicit), apenas que há um patamar mais adequado e mais fundamental de tratamento destes termos. Em segundo lugar, é justamente pelo fato de não haver átomos ontológicos últimos, unidades fáticas que são objeto dos juízos onde estes operam discretamente, que me sinto autorizado a associar a filosofia de Brandom com a ontologia de processo como sua contraparte ontológica. É claro que não me parece de todo que esta seja uma questão de Brandom. Ele se perguntar ou não por uma ontologia sem sentido, tendo em vista o papel transcendental que a concepção pragmático-inferencial de linguagem desempenha em sua filosofia.
} 
arquimediana que permita transitar entre os níveis teórico-metafísicos e explicitar a dinâmica interna de cada nível.

\section{Referências bibliográficas}

BAR-HILLEL, Y. An examination of information theory. In: Philosophy of Science, v.22, 1955, p. 86-105.

BRANDOM. Between Saying and Doing: Towards an Analytic Pragmatism. Oxford: Oxford University Press, 2008.

BRANDOM. Making it Explicit:Reasoning, Representing and Discursive Commitment. Cambridge: Harvard University Press, 1998.

BURGIN, Mark. Theory of Information: Fundamentality, Diversity and Unification. Singapore: World Scientific Publishing Company, 2010.

CHAITIN, Gregory J. Algorithmic Information Theory [ $3^{\text {rd }} \mathrm{ed}$ ]. Cambridge: Cambridge University Press, 1997.

CHAITIN, Gregory J. From Philosophy to Program Size, Key Ideas and Methods: Lecture Notes on Algorithmic Information Theory. Tallinn: Institute of Cibernetics: 2003.

COVER, T. M.; THOMAS, J. A. Elements of Information Theory. New Jersey: Wiley-Interscience, 2006.

CUMMINS, R. Meaning and Mental Representation. Bradford Books, 1991.

DOUSA, T. M.; IBEKWE-SANJUAN, F. Studies in History and Philosophy of Science: Theories of Information, Communication and Knowledge. A Multidisciplinary Approach. New York: Springer, 2014.

DRETSKE, F. Knowledge and the Flow of Information. Stanford: CSLI Publications, 1999.

FLORIDI, L. The Method of Levels of Abstraction. In: Minds \& Machines, v.18, 2008. p. 303-329.

FLORIDI, L. The Philosophy of Information. Oxford: Oxford University Press, 2011.

FLORIDI, L; ILLARI, P. (Eds.) The Philosophy of Information Quality. New York: Springer, 2014.

FLORIDI, L; SANDERS, W. Levellism and the Method of Abstraction In: GRECO, G. M. (Ed.). IEG Research Report. Oxford University - University of Bari: Information Ethics Group, 2004. Disponível em: http://web.comlab.ox.ac.uk/oucl/research/ areas/ieg. Acesso em: 20. Out. 2019.

GEACH, P. On What There Is. In: Proceedings of the Aristotelian Society, Suppl. v. XXV, 1951. p. 125-136.

HINTIKKA, J. On Semantic Information. In: HINTIKKA, J.; SUPPES, P. Information and Inference. Dordrecht: D. Reidel Publishing Company, 1970a. p. 3-27.

HECK, R. L. Informação a Partir de Regras: Considerações para a Solução do Escândalo da Dedução pela Semântica Inferencial Pragmática. Fortaleza. 146p. Tese (Doutorado em Filosofia). Universidade Federal do Ceará (UFC), 2018.

KAISER, Ł. Logic and Games on Automatic Structures:Playing with Quantifiers and Decompositions. New York: Springer, 2011.

KOMOLGOROV, A. N. Logical Basis for Information Theory and Probability Theory. In: IEEE Transactions on Information Theory. Vol.14, n. 5, New Jersey: IEEE Information Theory Society, 1968. p. 662-664.

KOMOLGOROV, A. N. Three approaches to the quantitative definition of information. In: International Journal of Computer Mathematics. v. 2, Philadelphia: Gordon and Breach Science Publishers, 1968, p. 157-168. 
LAMBALGEN, M. van. Algorithmic Information Theory. In: The Journal of Symbolic Logic, v. 54, n. 4, p. 1389-1400.

LOSEE, R. M. A Discipline Independent Definition of Information. In: Journal of The American Society for Information Science. n. 48 v. 3, 1997, p. 254-269.

MASLIN, K. T. Introdução à Filosofia da Mente. Porto Alegre: Artmed, 2009.

MOURELATOS, A. P. D. Events, Processes, and States. In: Linguistics and Philosophy, n. 2 v. 3, 1978. p. 415-434.

OLIVEIRA, M. A. de. Ontologia em Debate no Pensamento Contemporâneo. São Paulo: Paulus, 2014.

OLIVEIRA, M. A. A Metafísica do Ser Primordial. São Paulo: Loyola, 2019.

RESCHER, N. Process Metaphysics: An Introduction. New York: SUNY, 1996.

RYLE, G. The Concept of Mind. New York: Barnes and Noble, 1949.

SAGÜILLO, J. M. Hintikka on Information and Deduction. In: Teorema. vol. XXXIII/2, Oviedo: Universidad de Oviedo, 2014. pp. 75-88.

SEIBT, J. Quanta, Tropes, or Processes: On Ontologies for QFT beyond the Myth of Substance. In: Meinard Kuhlmann, Holger Lyre and Andrew Wayne, (Eds.). Ontological Aspects of Quantum Field Theory. Singapore: World Scientific, 2002. p. 53-93.

SEIBT, J. Ontologia de Processo. In: IMAGUIRE, G.; ALMEIDA C.L.S.de.; OLIVEIRA, M. A. de. (Orgs.). Metafísica Contemporânea. Petrópolis: Vozes, 2007.

SHANNON, C. E. Collected Papers. Sloane, N. J. A.; Wyner, A. D. (Eds.) New York: IEEE Press, 1993. SOMMARUGA, G. (Ed.) Formal Theories of Information: From Shannon to Semantic Information Theory and General Concepts of Information. Berlin: Springer, 2009.

STONIER, T. Beyond information: The natural history of intelligence. Berlin: Springer, 1992.

WHITEHEAD, A. Process and Reality, New York: Macmillan, 1929.

WITTGENSTEIN, L. Philosophical Investigations [1953]. 4ª ed. Oxford: Blackwell, 2009.

Sobre o autor

Ralph Leal Heck

Graduado em Filosofia pela UECE; Mestre em Filosofia pela UFC; Doutor em Filosofia pela UFC. Atuante no Departamento de Filosofia (UECE e Faculdade Católica de Fortaleza). Áreas de atuação: Filosofia Analítica, Lógica, Filosofia da Linguagem, Filosofia da Ciência e Filosofia da Informação. 